\title{
Effects of Chromic Treatment on the Surface Properties of Polypropylene (PP) Wood Composites
}

\author{
Marouan Rejeb ${ }^{1}$, Ahmed Koubaa ${ }^{1, *} \mathbb{0}$, Fayez Elleuch ${ }^{1,2}$, François Godard ${ }^{1,3}$, Sébastien Migneault ${ }^{1}$, \\ Besma Bouslimi ${ }^{1}$, Mohamed Khlif ${ }^{2}{ }^{-1}$ and Hatem Mrad $^{3}$ \\ 1 Laboratoire de Biomatériaux, Université du Québec en Abitibi-Témiscamingue, \\ Rouyn-Noranda, QC J9X 5E4, Canada; marouan.rejeb@uqat.ca (M.R.); Fayez.elleuch@uqat.ca (F.E.); \\ Francois.godard@uqat.ca (F.G.); Sebastien.migneault@uqat.ca (S.M.); Besma.Bouslimi2@uqat.ca (B.B.) \\ 2 Laboratoire des Systèmes Électromécaniques (LASEM), École Nationale d'Ingénieurs de Sfax, \\ Sfax 3038, Tunisia; khlifmohamed@yahoo.fr \\ 3 École de Génie, Université du Québec en Abitibi-Témiscamingue, Rouyn-Noranda, QC J9X 5E4, Canada; \\ Hatem.mrad@uqat.ca \\ * Correspondence: ahmed.koubaa@uqat.ca; Tel.: +1-819-762-0971 (ext. 2579)
}

Citation: Rejeb, M.; Koubaa, A.; Elleuch, F.; Godard, F.; Migneault, S.; Bouslimi, B.; Khlif, M.; Mrad, H. Effects of Chromic Treatment on the Surface Properties of Polypropylene (PP) Wood Composites. Coatings 2021 11, 851. https://doi.org/10.3390/ coatings11070851

Received: 12 June 2021

Accepted: 12 July 2021

Published: 15 July 2021

Publisher's Note: MDPI stays neutral with regard to jurisdictional claims in published maps and institutional affiliations.

Copyright: (c) 2021 by the authors. Licensee MDPI, Basel, Switzerland. This article is an open access article distributed under the terms and conditions of the Creative Commons Attribution (CC BY) license (https:// creativecommons.org/licenses/by/ $4.0 /)$

\begin{abstract}
The moisture sensitivity of wood-polymer composites (WPCs) is mainly related to their hydrophilic wood components. Coatings are among the alternatives that improve the dimensional stability of these composites. However, the adhesion of most coatings to the WPC surface is generally poor. Thus, chemical and/or mechanical treatments should be applied to the WPC surface to improve the coating adhesion. Therefore, the main objective of this study was to improve the adhesion coating of polypropylene (PP) WPCs through a chromic treatment. PP was reinforced by three different pulp fibers (kraft, thermomechanical (TMP), and chemothermomechanical (CTMP)) at three fiber contents $(50,60$, and $70 \% w / w)$. A chromic treatment was applied to the PP-based WPCs to activate the surface of the composites and alter their roughness parameters, creating a higher interfacial zone that improved the bonding of the epoxy coating to the surface of the PP composites. The chromic treatment increased the roughness of the surface. An increase in profile and surface parameters was observed after treatment. This treatment modified the chemical composition of the surface by creating polar carbon-oxygen groups and increasing the carbonyl and hydroxyl indexes.
\end{abstract}

Keywords: wood-polymer composites; chromic treatment; roughness parameters; carbonyl index; hydroxyl index; surface treatment

\section{Introduction}

Wood-polymer composites (also called wood-plastic composites, WPCs) are materials that combine two or more distinct components: the polymer as a matrix and the lignocellulosic fiber as reinforcement. The use of WPCs in humid environments requires good resistance to water absorption and swelling. Their sensitivity to moisture is mainly due to the presence of hydroxyl groups from the lignocellulosic components [1]. To improve WPC behavior for exterior use, it is relevant to consider protective coatings. However, knowledge of the surface properties of the composite is essential for the development of a suitable coating system. Indeed, adhesive bonding is necessary for the assembly of WPCs and the application of coatings. WPCs have low surface energy and poor adhesion properties. In this respect, the adhesion of the coating to a WPC can be improved by surface pretreatments, especially for composites that contain polyolefins as their contact surface is not active. The most effective surface treatments increase surface energy (especially the polar component) and produce surface oxidation. The improvement of the adhesion of WPCs depends on wood content, the nature of the polymer, and surface roughness [2].

The most effective method for improving the adhesion of the coating on a surface is to apply surface treatments, which will enhance wettability. These treatments include plasma 
and corona techniques that activate the wood surface and improve its wettability [3]. Wolkenhauer et al. [4] reported that plasma treatment of wood surfaces is superior to sanding for increasing surface energy, which is even more important when combining the two techniques.

The surface heterogeneity and lack of adhesion of coatings to WPCs are a result of inactive plastic on the surface [2]. Polyolefins are polymers with low surface energy that do not have a polar component, making it difficult to coat plastic onto their surfaces. The surface treatment of polyolefin has been studied to improve many properties, such as adhesion, wettability, roughness, printability, transparency, and lubricity, by introducing polar groups or surface roughening. Several surface modification techniques have been applied to polyolefins, e.g., chemical etching with sulfuric acid or chromic acid, physical etching, flame, corona discharge, and plasma treatment [5]. These surface treatments have a limited lifetime and require a rapid coating of the activated surface [6].

It is expected that surface activation processes can improve coating adhesion to WPCs due to the presence of plastic on the surface. Akhtarkhavari et al. [7] reported improved paint adhesion after a surface pretreatment of compression-molded WPCs. Similarly, Oporto et al. [8] studied the shear strength of epoxy adhesive with extruded WPCs. They reported an increase in the shear strength of both wet and dry adhesives after sanding and flame treatment. To date, there has been little systematic evaluation of potential surface activation techniques on the adhesion of coatings to WPCs.

The surface inactivity of WPCs is mainly attributed to the hydrophobic nature of the polymer matrices, whose effect is more noticeable than the wood content. Gupta et al. [2] listed surface activation pretreatment methods that improve adhesion properties: oxygen plasma treatment, chromic acid treatment, flame treatment, and UV/BP treatment. This study showed that the surface treatment of WPCs with chromic acid was the most effective due to the chemical modifications made to the surface. Gramlich et al. [9] found that surface treatment with flames, water, or a combination of the two improves the shear strength of adhesive joints made with polyolefin WPCs, but not as much as a chromic acid treatment. Yáñez-Pacios et al. [10] proposed ultraviolet (UV) and ozone treatments to improve WPCs ${ }^{\prime}$ surface energy and peel strength. According to Mirabedini et al. [11], exposing PP films to microwave irradiation in the presence of potassium permanganate (PPM) was found to be simple and effective. It is a means to improve the wettability of the polymer surfaces. According to FTIR data, oxidation reactions can occur on the PP surface. The adhesion tests showed an increase in the bonding strength of the acrylic-based lacquer on PP samples [11].

Oporto et al. [8] studied the effect of a chromic treatment on the surface of WPCs made from pine flour and polypropylene. This treatment allowed for an increase in the oxygen content on the surfaces and showed the highest surface energy values. These results suggested that the strong bonding of WPCs with epoxy resin could be attributed to acid-based interactions. Chromic acid etching is a process for modifying the surface of polymer wood composites. The chromic solution is usually prepared by mixing dichromate and sulfuric acid at room temperature according to the ASTM D 2093 standard method [12]. Blais et al. [13] conducted a thorough study of chromic etching and suggested that surface removal rate improves with a higher temperature and longer reaction time.

Teng et al. [14] demonstrated that the surface of the wood/polyethylene composites decreased and the surface's wettability improved after liquid oxidation; the functional groups -C-O- and $\mathrm{C}=\mathrm{O}$ were formed on the treated surface, and the surface roughness increased. Thus, after treatment, the shear bond strength of the treated sample increased significantly.

The adhesion of the coating to the composite also depends on the nature of the coating. The effectiveness of the WPC surface treatment also depends on the wood content, the nature of the polymer, and the surface roughness. Moghadamzadeh et al. [15] followed the evolution of oxidized groups on FTIR spectra. To this end, they focused on the carbonyl and hydroxyl group indexes calculated from the intensities of the different peaks. The peak at $3344.71 \mathrm{~cm}^{-1}$ corresponded to hydroxyl groups $(-\mathrm{OH})$ bound to cellulose or hemicellulose. 
The peak at $2916.4 \mathrm{~cm}^{-1}$ corresponded to the (-CH) methyl and methylene groups. The $1454.39 \mathrm{~cm}^{-1}$ peak corresponded to the hydrocarbon chains of the $\left(\mathrm{CH}_{2}\right)$ groups.

The chromic treatment implies a manual or mechanical abrasion step, carried out using sandpaper. It is an essential step to prepare the surface. On the other hand, mechanical abrasion is one of the methods used to improve the surface activity of WPCs. This process increases the roughness and hydroxyl and wood content of the surface [16]. Indeed, the mechanical treatment effectively removes the surface layers and exposes the wood to the surface layer.

According to the literature, the chromic treatment showed the best results in surface activation compared to other techniques for surface activation. According to Table 1, the roughness parameters were more pronounced following this treatment. The chromic treatment also provided one of the lowest contact angle measurements, suggesting better wettability. Ryntz [17] compared different pretreatment methods, including chromic acid, plasma, flame, and UV. This study showed that the chromic acid treatment had a high oxygen content and subsequent total oxidation.

Table 1. Effect of different surface treatments on the surface properties of wood-polymer composites.

\begin{tabular}{|c|c|c|c|c|c|c|c|}
\hline Pretreatment & Effects & Ref & $\mathrm{O}=\mathrm{C} / \mathrm{C}-\mathrm{H}^{\mathrm{a}}$ & $\mathrm{O}-\mathrm{H} / \mathrm{C}-\mathrm{H}^{\mathrm{a}}$ & $\begin{array}{c}\text { Roughness } \\
\text { Amplitude } \\
\text { (̊) }\end{array}$ & $\begin{array}{c}\text { Peel } \\
\text { load } \\
(\mathrm{N} / \mathrm{m})^{a}\end{array}$ & $\begin{array}{c}\text { Contact Angle } \\
\left({ }^{0}\right)\end{array}$ \\
\hline $\begin{array}{l}\text { Oxygen } \\
\text { plasma }\end{array}$ & $\begin{array}{l}\text { Carbon-carbon chain } \\
\text { scission in PE. } \\
\text { Crosslinking in PP. } \\
\text { Incorporation of oxygen } \\
\text { moieties. }\end{array}$ & $\begin{array}{c}{[18]} \\
{[2]} \\
{[19]}\end{array}$ & 3.14 & 1.97 & 1.99 & 516 & $35 \pm 14^{a}$ \\
\hline $\begin{array}{c}\text { Flame } \\
\text { treatment }\end{array}$ & $\begin{array}{l}\text { Generation of alkoxy, } \\
\text { peroxy, and hydroperoxy } \\
\text { groups to react with the } \\
\text { polyolefins in a free radical } \\
\text { pathway by forming } \\
\text { reactive substrates. } \\
\text { Increasing epoxy adhesive } \\
\text { shear strength with } \\
\text { extruded WPCs. }\end{array}$ & $\begin{array}{c}{[20]} \\
{[21]} \\
{[2]}\end{array}$ & 1.83 & 1.7 & 3.4 & 381 & $104 \pm 14^{\mathrm{a}}$ \\
\hline $\begin{array}{l}\text { Benzophenone/ } \\
\text { Ultraviolet } \\
\text { (BP/UV) }\end{array}$ & $\begin{array}{l}\text { Becomes photo-excited to } \\
\text { high energy states in UV } \\
\text { radiation and undergoes } \\
\text { reactive collision with the } \\
\text { polymer substrates to create } \\
\text { active polyolefins. }\end{array}$ & $\begin{array}{c}{[22]} \\
{[2]}\end{array}$ & 1.89 & 1.25 & 2.48 & 466 & $92.08-104.98^{b}$ \\
\hline $\begin{array}{l}\text { Chromic acid } \\
\text { etching }\end{array}$ & $\begin{array}{l}\text { Leads to chain cleavage and } \\
\text { the formation of polar } \\
\text { groups on the polyolefins. } \\
\text { Oxidize the polymer to } \\
\text { create an } \\
\text { oxygen-rich surface with } \\
\text { alcohols, carbonyls, and } \\
\text { some chromium complexes. }\end{array}$ & $\begin{array}{c}{[23]} \\
{[2]} \\
{[24]}\end{array}$ & 1.63 & 1.01 & 5.22 & 637 & $65.49-80.26^{b}$ \\
\hline $\begin{array}{l}\text { Corona } \\
\text { treatment }\end{array}$ & $\begin{array}{l}\text { The corona treatment was } \\
\text { superior in terms of acrylate } \\
\text { paint adhesion compared to } \\
\text { the sanding and wheat } \\
\text { starch blasting }\end{array}$ & [7] & - & - & - & - & - \\
\hline
\end{tabular}


To our knowledge, few or no studies have investigated the effect of chromic treatment on composites highly filled with paper fibers. This study allowed us to understand the effects of this treatment on the surface properties of such composites produced by an injection molding process. The main objective of this work was to study the impact of chromic pretreatment on the surface properties of polypropylene-based WPCs to improve the wettability of composites before the application of coatings. The specific objectives were to determine the effect of this treatment on the surface roughness of composites and to evaluate the effect of chromic treatment on the surface chemistry of composites.

\section{Materials and Methods}

\subsection{Materials}

Polypropylene (PP) (NexeoSolutions, The Woodlands, TX, USA) with a density of $0.903 \mathrm{~g} \mathrm{~cm}^{-3}$, and a $20 \mathrm{~g} / 10 \mathrm{~min}$ melt index, three types of fibers from three papermaking processes (kraft provided by Domtar Inc., Windsor, QC, Canada, thermomechanical (TMP) obtained from Resolu Amos, QC, Canada, and chemi-thermomechanical (CTMP) provided by the Université du Québec à Trois-Rivières, Trois Rivières, QC, Canada) at three different fiber proportions (50,60, and 70\%, weight basis) were used for WPC manufacturing. STRUKTOL ${ }^{\circledR}$ TPW 113 from Struktol Company of America (Stow, OH, USA) was used as a coupling agent at a rate of $5 \%$ on a weight basis.

\subsection{Composite Manufacturing}

WPCs were manufactured according to a factorial plan where the factors were polymer fiber type (kraft, TMP, CTMP) and fiber proportion (50,60, and 70\%). A total of 9 formulations were prepared. The blends were extruded into wood-polymer pellets using a twin-screw extruder (Thermo Scientific HAAKE PolyLab OS Rheodrive 7 with Rheomex OS extruding module, Thermo Electron $\mathrm{GmbH}$, Karlsruhe, Germany). The temperature profile was $160-170-180^{\circ} \mathrm{C}$, and the rotation speed was $70 \mathrm{rpm}$. The pellets were then dried for $24 \mathrm{~h}$ at $80^{\circ} \mathrm{C}$. The last step consisted of manufacturing standard test samples using an injection molding machine (Haitian MA600II/130, Ningbo, China).

\subsection{Surface Chemical and Physical Properties}

The surface chemistry of coated and uncoated WPCs was investigated by Fourier Transform Infrared Spectroscopy (FTIR), which allows the detection of chemical functions in the material via the characteristic vibrations of each chemical bond. The FTIR was performed on small composite samples using the Shimadzu IRTracer-100 spectrometer (Kyoto, Japan) equipped with an attenuated total reflectance (ATR). The FTIR was performed by applying a baseline correction under an absorption measurement mode. The number of scans was 64 with a resolution of 8 in the range of $500-4000 \mathrm{~cm}^{-1}$. For each formulation, two measurements were taken.

Carbonyl and hydroxyl indexes were computed according to Equations (1) and (2) [15], respectively.

$$
\begin{aligned}
& I \text { carbonyl }=\frac{\mathrm{I} 1454.39}{\mathrm{I} 3344.71} \\
& \mathrm{I} \text { hydroxyl }=\frac{\mathrm{I} 2916.4}{\mathrm{I} 3344.71}
\end{aligned}
$$

Stark et al. [25] introduced the wood index (I wood) for surface cellulosic hydroxyl groups. It was measured by normalizing the cellulosic hydroxyl peak intensity at $1023.9 \mathrm{~cm}^{-1}$ for the polyolefinic vC-H stretching peak intensity at $2916.4 \mathrm{~cm}^{-1}$ (Equation (3)).

$$
\mathrm{I} \operatorname{wood}=\frac{\mathrm{I} 1023.89}{\mathrm{I} 2916.4}
$$

Surface roughness parameters were measured using a Keyence VK-X150 LASER confocal microscope (Itaska, IL, USA). Measured parameters were the arithmetic mean 
height for a roughness profile $(R a)$, maximal profile height $(R z)$, arithmetic mean height $(S a)$, and maximal areal height $(S z)$. These parameters are defined as follows [26,27]:

$R a$ : Arithmetic mean height expressed in micrometers $(\mu \mathrm{m})$ when sampling only the reference length from the roughness curve in the direction of the mean line, taking the $X$-axis in the direction of the mean line and the $Y$-axis in the direction of longitudinal magnification of this sampled part, and the roughness curve is expressed by $y=Z(x)$ (Equation (4)).

$$
R a=\frac{1}{l r} \int_{0}^{l r}|Z(x)| d x
$$

Ir: Sampling length

$R z$ : The maximum height of the profile indicates the absolute vertical distance between the maximum profile peak height and the maximum profile valley depth along the sampling length (Equation (5)).

$$
R z=R v+R p=|\min (Z(x))|+\max (Z(x))
$$

$R v$ : Maximum profile valley depth (for a roughness profile);

$R p$ : Maximum profile peak height (for a roughness profile).

The arithmetic mean height $(S a)$ is the mean of the absolute value of the height of points within the defined area (Equation (6)).

$$
S a=\frac{1}{A} \iint_{A}|Z(x, y)| d x d y
$$

$S z$ : This parameter is defined as the sum of the largest peak height value and the largest pit depth value within the defined area (Equation (7)).

$$
S z=S v+S p=\left|\min _{A}(Z(x))\right|+\max _{A}(Z(x))
$$

Sp: maximum peak height;

Sv: maximum pit height.

\subsection{Contact Angle}

A Goniometer (DataPhysics company model OCA 15EC; Filderstadt, Germany) was used to perform the contact angle measurements. The images were analyzed with SCA 26 software. The contact angle measurement accuracy is $\pm 3^{\circ}$. Three repetitions were performed for each formulation ( 9 formulations $* 2$ treatments (untreated, treated) $* 3$ repetitions).

\subsection{Statistical Analysis}

The surface properties $(R a, R z, S a$, and $S z)$, chemical properties (carbonyl, hydroxyl, and wood indexes), and contact angle were subjected to an analysis of variance using the ANOVA procedure and customized factorial model using the SAS statistical package, version 9.4 (SAS, 2008). Studied factors were fiber type (kraft, CTMP, and TMP), fiber proportion $(0,50,60$, and $70 \%)$, and treatment (untreated and chromic treatment). All factors were considered fixed. Effects and differences between means were considered statistically significant at $p<0.05$. A graphical analysis of the residuals verified the variance homogeneity, and no transformation was used.

\section{Results and Discussion}

\subsection{Analysis of Variance}

The analysis of variance (Table 2) investigated the impact of the studied factors (fiber type, fiber proportion, and treatment) and their interactions on the roughness parameters, surface chemistry, and contact angle. The carbonyl, hydroxyl, wood indexes, and the contact angle all significantly varied with the fiber type and proportion changes, and 
the treatment (Table 2). Regarding the surface properties, only the fiber content and the treatment had highly significant effects $(\alpha=0.0001)$. This indicates that the chromic treatment had a significant effect on the surface roughness of the composites.

Table 2. Analysis of variance, with F-values for the studied factors (fiber type, fiber proportion, treatment, and their interactions), and their significance, for roughness parameters, surface chemistry, and composites contact angle.

\begin{tabular}{|c|c|c|c|c|c|c|c|c|c|}
\hline \multirow{3}{*}{ Source } & \multirow{3}{*}{$\mathrm{DF}^{1}$} & \multicolumn{4}{|c|}{ Roughness Parameters } & \multicolumn{3}{|c|}{ Surface Chemistry } & \multirow{2}{*}{$\begin{array}{c}\text { Contact } \\
\text { Angle }\end{array}$} \\
\hline & & $\mathbf{R a}$ & $\mathbf{R z}$ & Sa & $\mathrm{Sz}$ & $\begin{array}{l}\text { Carbonyl } \\
\text { Index }\end{array}$ & $\begin{array}{l}\text { Hydroxyl } \\
\text { Index }\end{array}$ & $\begin{array}{l}\text { Wood } \\
\text { Index }\end{array}$ & \\
\hline & & \multicolumn{8}{|c|}{ F-Value } \\
\hline Fiber type (F) & 2 & $0.2^{\text {n.s. }}$ & $4.2 *$ & $0.4^{\text {n.s. }}$ & $6.8 *$ & $2.6^{\text {n.s. }}$ & $8.3^{*}$ & $20.9 * *$ & $41.9^{* *}$ \\
\hline Fiber proportion $(\mathrm{P})$ & 3 & 12. $7^{* *}$ & $56.6^{* *}$ & $11.1^{* *}$ & $11.9^{* *}$ & $134.9^{* *}$ & $145.8^{* *}$ & $65.1^{* *}$ & $28.7^{* *}$ \\
\hline Treatment $(\mathrm{T})$ & 1 & $105.5^{* *}$ & $223.3^{* *}$ & $246.1^{* *}$ & $11.6^{* *}$ & $130.0^{* *}$ & $106.7^{* *}$ & $144.3^{* *}$ & $245.7^{* *}$ \\
\hline $\mathrm{F} \times \mathrm{P}$ & 6 & $0.9^{\text {n.s. }}$ & $5.5 *$ & $0.7^{\text {n.s. }}$ & $0.9^{\text {n.s. }}$ & $10.0 * *$ & $14.9 * *$ & $3.2 *$ & $9.8^{* *}$ \\
\hline $\mathrm{F} \times \mathrm{T}$ & 2 & $0.5^{\text {n.s. }}$ & $4.6^{*}$ & $0.7^{\text {n.s. }}$ & $5.1 *$ & $33.8 * *$ & $43.9 * *$ & $8.6^{*}$ & $3.1^{\text {n.s. }}$ \\
\hline $\mathrm{P} \times \mathrm{T}$ & 3 & $1.1^{\text {n.s. }}$ & $5.0 *$ & $2.2^{\text {n.s. }}$ & $9.6 *$ & $9.1 *$ & $9.9 *$ & $24.3^{* *}$ & $18.8^{* *}$ \\
\hline $\mathrm{F} \times \mathrm{P} \times \mathrm{T}$ & 6 & $0.1^{\text {n.s. }}$ & $1.7^{\text {n.s. }}$ & $0.1^{\text {n.s. }}$ & $0.9^{\text {n.s. }}$ & $7.1 *$ & $8.6^{* *}$ & $1.6^{\text {n.s. }}$ & $4.4 *$ \\
\hline
\end{tabular}

$\mathrm{DF}^{1}$ : degree of freedom; **: significant at $\alpha=0.0001$; $^{*}$ : significant at $\alpha=0.05 ;$ n.s.: non-significant at $\alpha=0.05$.

\subsection{Effect of Chromic Treatment on Surface Chemistry}

The surface chromic treatment led to important increases in the carbonyl (Figure 1a) and hydroxyl (Figure 1b) indexes of kraft and TMP composites. For the CTMP composites, both indexes increased for the $70 \%$ fiber WPC, remained constant for the $60 \%$ fiber content WPC, and decreased for the $50 \%$ fiber content composites.

It has been proven that the reaction mechanism of chromium VI in the chromic acid solution on the surface is the cross-linking and cleavage of the PP polymer chain [28]. Specifically, the wood index designates the quantity of wood present on the surface [25], which is the ratio of the two peaks of the spectrum at 2916.4 and $1033.89 \mathrm{~cm}^{-1}$ (Equation (5)) associated with the wood and polymer, respectively. The wood index increased with fiber proportion and decreased after the chromic treatment (Figure 1c).

The wood index dropped considerably after the chromic treatment, showing that PP-based composites have a surface layer that is rich in the polymer. This index increases with the fiber content and is more important in the case of kraft-based WPCs. This can be explained by the higher cellulose content in the kraft fiber compared to TMP and CTMP fibers. However, after chromic treatment, the wood index decreased for all formulations since the wood component was less exposed at the surface. There was also a decrease in the $\mathrm{OH}$-band intensity of the wood component at $3344.7 \mathrm{~cm}^{-1}$, indicating that the treated WPC surface was enriched with PP. This can be explained by the treatment temperature and its corrosive effect on the wood component.

The FTIR spectra for TMP-filled WPCs (Figure 2) showed the formation of a new $\mathrm{C}=\mathrm{O}$ band at $1712.9 \mathrm{~cm}^{-1}$, and a new $\mathrm{C}-\mathrm{O}-\mathrm{C}$ band appeared at $1253.8 \mathrm{~cm}^{-1}$ for TMP-based WPCs, showing more pronounced oxidation of the surfaces and higher polarity [29].

The results above indicate that the chromic treatment of PP-based WPCs limited the exposition of the wood chemical groups at the surface and exposed PP. Therefore, this treatment significantly changed the chemical composition of the surface. An improvement in oxidation is creating new carbon-oxygen polar groups and increasing the carbonyl and hydroxyl indexes. 


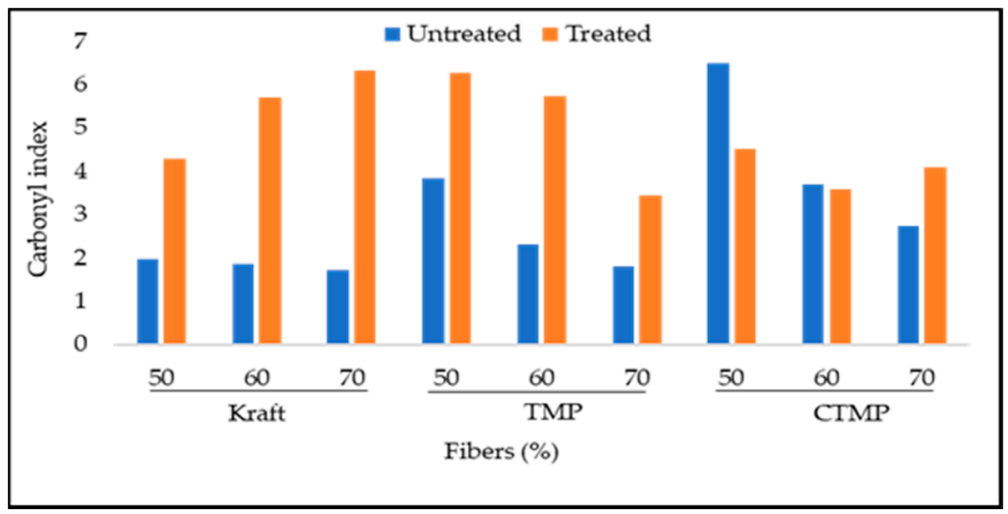

(a)

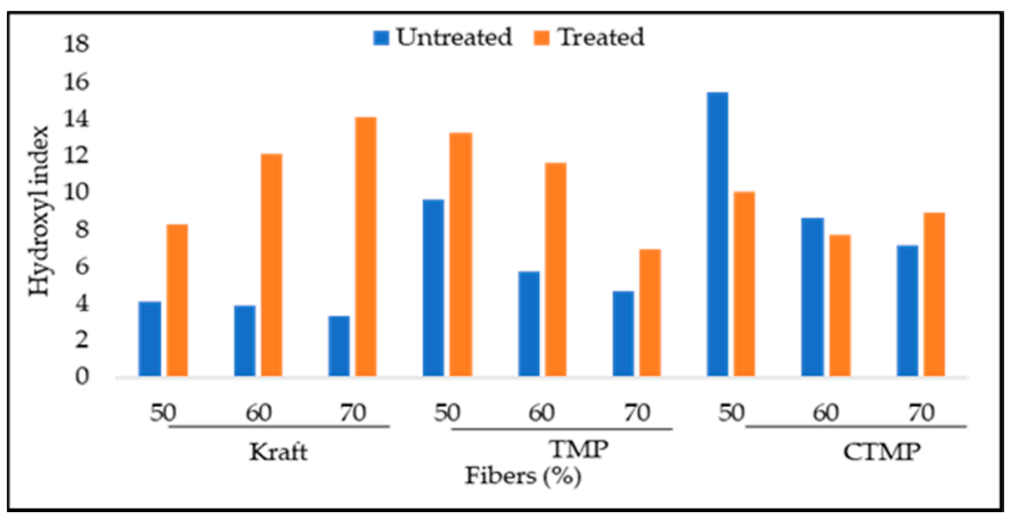

(b)

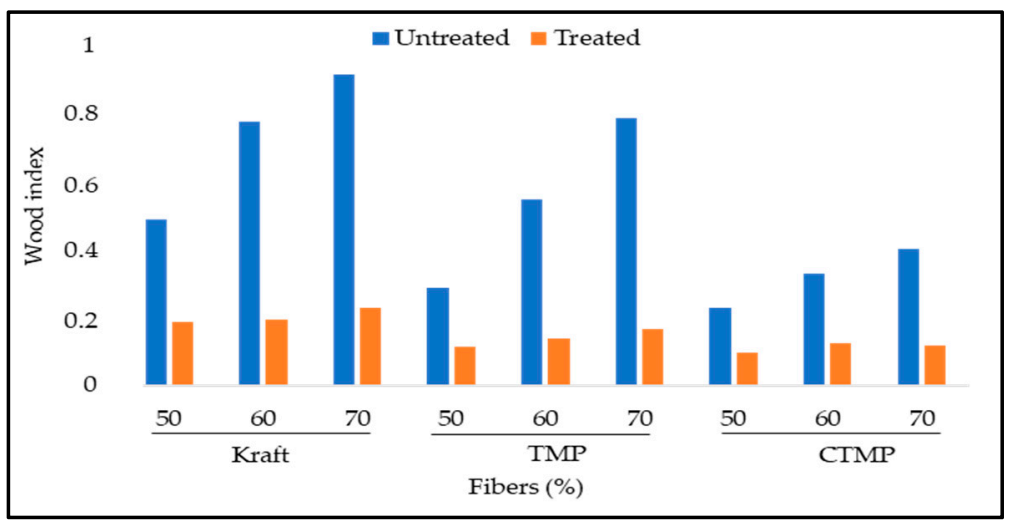

(c)

Figure 1. Effects of the chromic treatment on the surface chemistry of polypropylene-based composites before and after chromic treatment: (a) carbonyl index, (b) hydroxyl index, and (c) wood index.

Similar findings were reported by Mohamed et al. [24] when they compared the effects of different surface treatments on the chemical properties of composites. Their study mentioned that the chromic treatment led to the apparition of three new FTIR peaks, which were $3360\left(-\mathrm{OH}\right.$ band), $1610=(-\mathrm{C}=\mathrm{O})$, and $1065 \mathrm{~cm}^{-1}$ (-CO band) compared to untreated composites. These newly generated polar groups were of great benefit to the wettability and adhesion ability of wood/PE composites [24].

Gupta et al. [2] reported that the flame, UV/BP, and chromic treated WPCs have a similar O=C/C-H ratio to the untreated WPCs, not only due to the fact that oxidation did not occur but also likely owing to the higher concentration of the polyolefin $(\mathrm{C}-\mathrm{H})$ on the surface. Their study found that the chromic and UV/BP treatments showed the lowest $\mathrm{OH}-\mathrm{CH}$ ratios (1.01 and 1.25, respectively). 


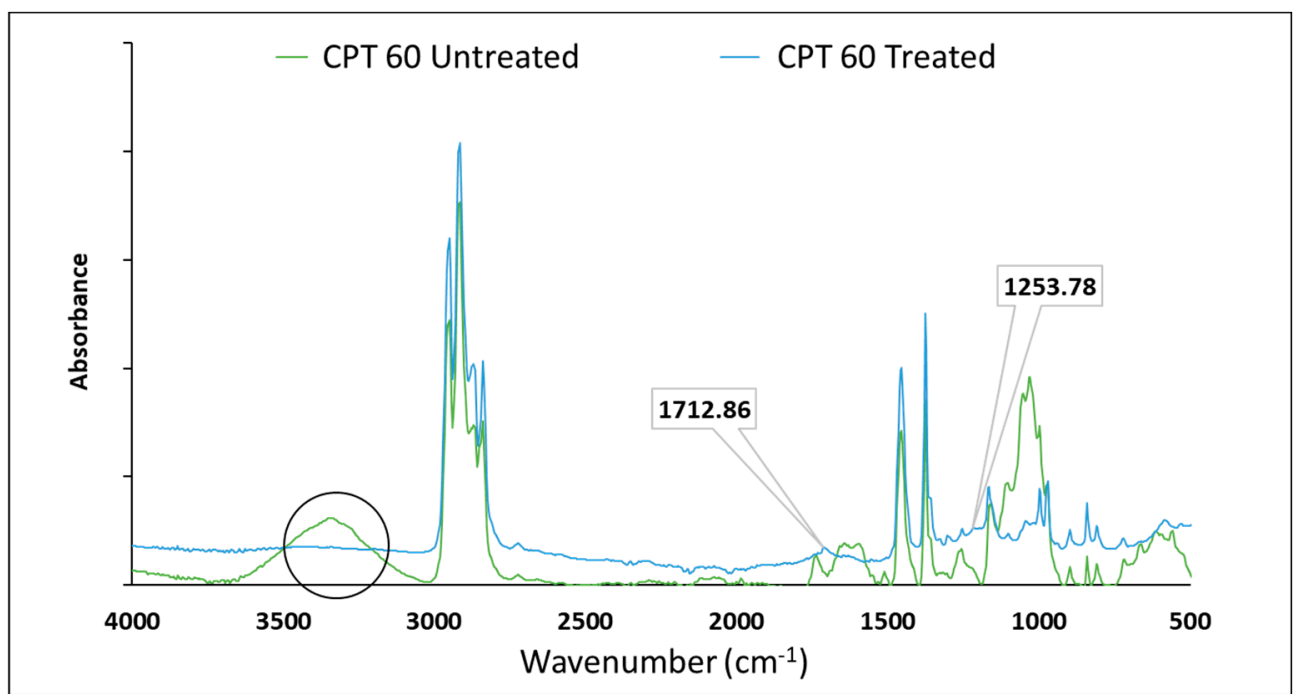

Figure 2. Fourier Transform Infrared Spectroscopy (FTIR) for treated and untreated composites (35\% polypropylene $+60 \%$ thermomechanical fiber).

\subsection{Effect of Chromic Treatment on Topography and Roughness}

Figures 3 and 4 show that roughness values depend on the type and content of the fibers before the chromic treatment. Indeed, the addition of fiber results in a rougher surface. A 5 and 25\% increase in Ra (Figure 3a) and Sa (Figure 4a), respectively, can be seen when switching from pure polymer to a 50\% kraft fiber-reinforced composite. Moreover, when increasing the fiber content, the roughness parameters evolve proportionally as the fiber content at the surface increases. Furthermore, kraft fiber-reinforced composites have the roughest surfaces. These results are consistent with the wood index results (Figure 1c) since kraft-based WPCs showed the highest indexes. As shown in Figures 3 and 4, a chromium treatment increases surface roughness. Indeed, the profile parameters ( $R a$ and $\mathrm{Rz}$ ) shown in Figure 3 and the surface parameters (Sa and Sz) shown in Figure 4 follow the same trend. Remarkably, the transition from a pure matrix to a high-fiber composite promotes roughness, with all composites having higher roughness values than pure PP.

Untreated composites showed a variation in all roughness parameters. The increase in fiber content increased Ra, Rz, Sa, and Sz. Ayrilmis et al. [30] reported that the rise in wood fiber content significantly increased the surface roughness of WPC samples. This was mainly attributed to the anatomical structure of the wood particles, such as caves (vessels and cell lumens). However, the nature of the fiber did not present an important change factor. Sieminsky et al. [31] reported that the wood species influenced the surface roughness properties. The surface roughness of high-density hardwoods was lower than that of low-density softwoods. This can be explained by the wood index, which remains almost uniform, regardless of fiber type and content after treatment. The Ra value for the untreated PP-composites filled with 50\% CTMP increased from 2.07 to $4.84 \mu \mathrm{m}$ after chromium treatment. The AFM and the profilometer showed higher amounts of roughness for all four parameters. Thus, the chromic acid treatment considerably increased WPC surface roughness. The chromic treatment probably resulted in cracks, pores, and surface pitting on the WPC surface. Moreover, the surface roughness caused a higher interfacial zone for bonding with the coating [2]. 


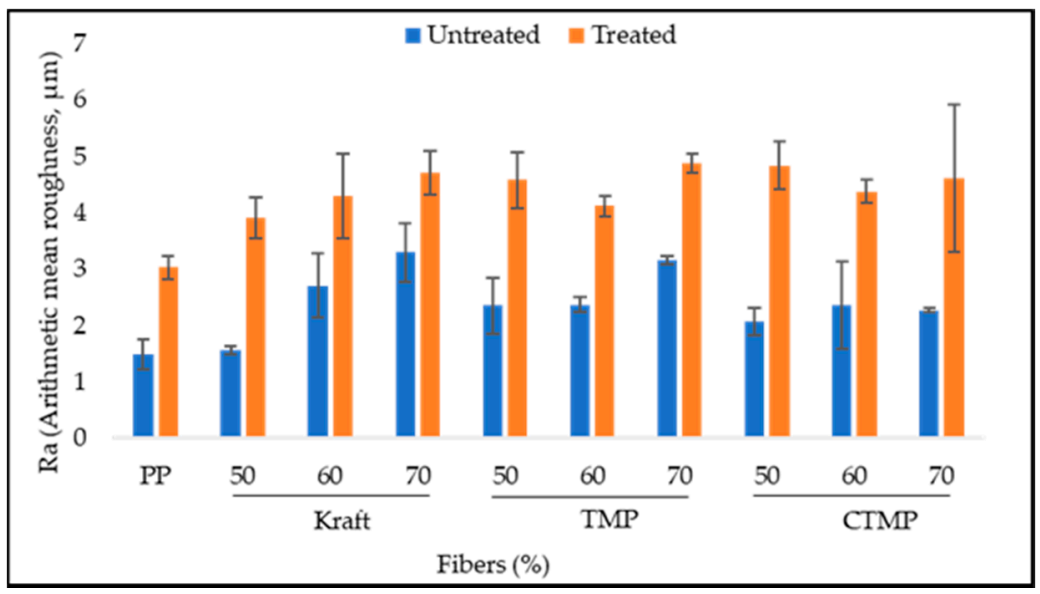

(a)

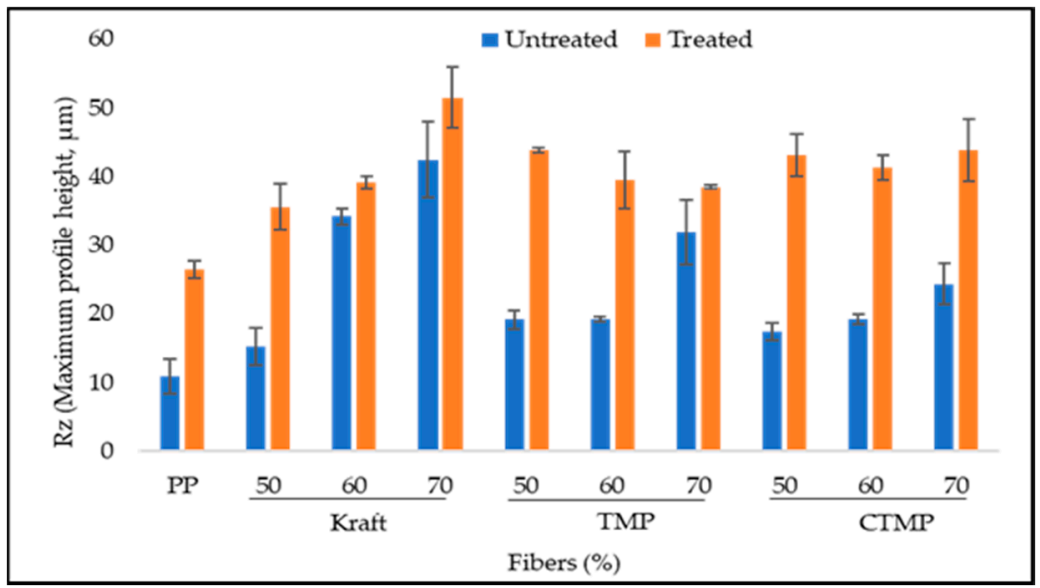

(b)

Figure 3. Evolution of profile roughness parameters (2D) of PP-based composites before and after chromic treatment: (a) arithmetic mean roughness evolution and (b) maximal profile height evolution.

The apparition of a new hydrophilic band and a higher amount of roughness demonstrated the efficiency of the chromic treatment. Mohamed et al. [24] measured the contact angle of composites treated with chromic acid, benzophenone/ultraviolet, and flame and heat. The chromic acid-treated WPCs showed the lowest contact angle, which indicated an enhancement of the hydrophilic character of the WPC surface. This could be attributed to the fact that chromic acid treatment functionalizes the WPC surface via an oxidative mechanism. In addition to their impact on WPC hydrophobicity, chromic treatments also affect adhesion. Indeed, Mohamed et al. [24] reported that the adhesion of WPCs treated with chromic acid is much higher than WPCs treated with the other two treatment methods. Gramlich et al. [9] found that chromic acid and flame retardment treatments caused the oxidation of both PP and wood, respectively, thus showing better WPC/epoxy bond strength. By increasing the fiber content in treated composites, the roughness values slightly varied.

Gupta et al. [2] compared the surface roughness of treated WPCs with chromic acid, oxygen plasma, flame, and UV/benzophenone (BP) treatments. The highest results were observed in WPCs treated with chromic acid $(5.22 \pm 2.3 \AA)$. Surface roughness causes a higher interfacial area for bonding, and possibly greater energy dissipation mechanisms for plastics. A significant increase in surface oxidation was reported in plasma-treated WPCs, and a related increase in wettability was observed. According to Gupta et al. [2], chromic treated WPCs clearly display larger variations in surface roughness than plasma $(1.99 \pm 0.6 \AA)$, $\mathrm{BP} / \mathrm{UV}(2.48 \pm 0.6 \AA)$, or flame $(3.4 \pm 1.9 \AA)$ treatments. Gupta et al. [2] showed that UV/BP and plasma-treated WPCs have a similar topography to the untreated composites. 


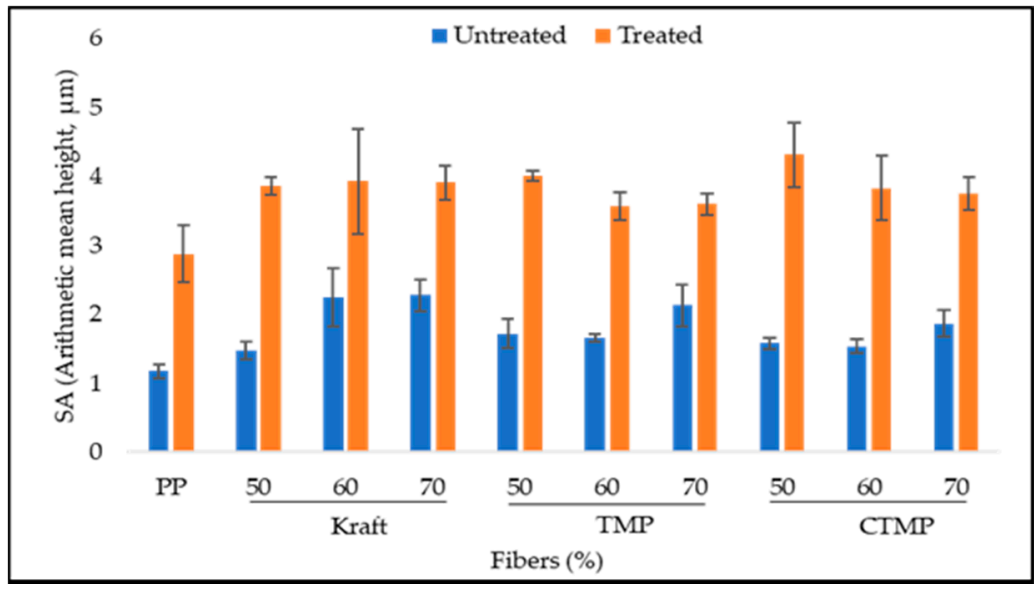

(a)

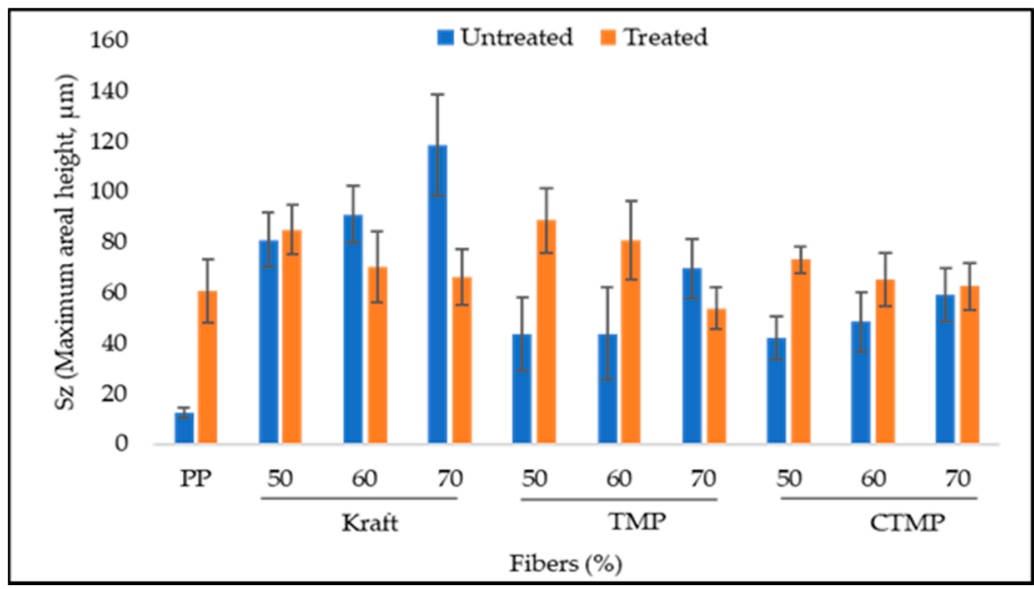

(b)

Figure 4. Evolution of surface roughness parameters (3D) of PP-based composites before and after chromic treatment: (a) arithmetic mean height evolution and (b) maximal areal height evolution.

\subsection{Effect of Chromic Treatment on Contact Angle}

The contact angles of the composites before chromic treatment were high (between 85 and $101^{\circ}$ ), which confirms that the composites are low-surface energy materials. Figure 5 shows that chromic treatment reduced the contact angle by up to $22 \%$ for composites loaded with $60 \%$ CTMP fiber. A minor decrease (about 3\%) was observed for composites filled with $50 \%$ Kraft fiber.

On average, the chromic treatment reduced the contact angle values by $12 \%$. A decrease in the contact angle resulted in better surface wettability. The work of Teng et al. [14] showed that the chromic treatment reduced the contact angle for wood-HDPE composites, and Moghadamzadeh et al. [15] noted a decrease in the contact angle from 83 to $60^{\circ}$ after the chromic treatment on 30\% HDPE and 70\% wood composites. This decrease indicated an improvement in the surface free energy and promoted the adhesion of the coatings to the composite surface. 


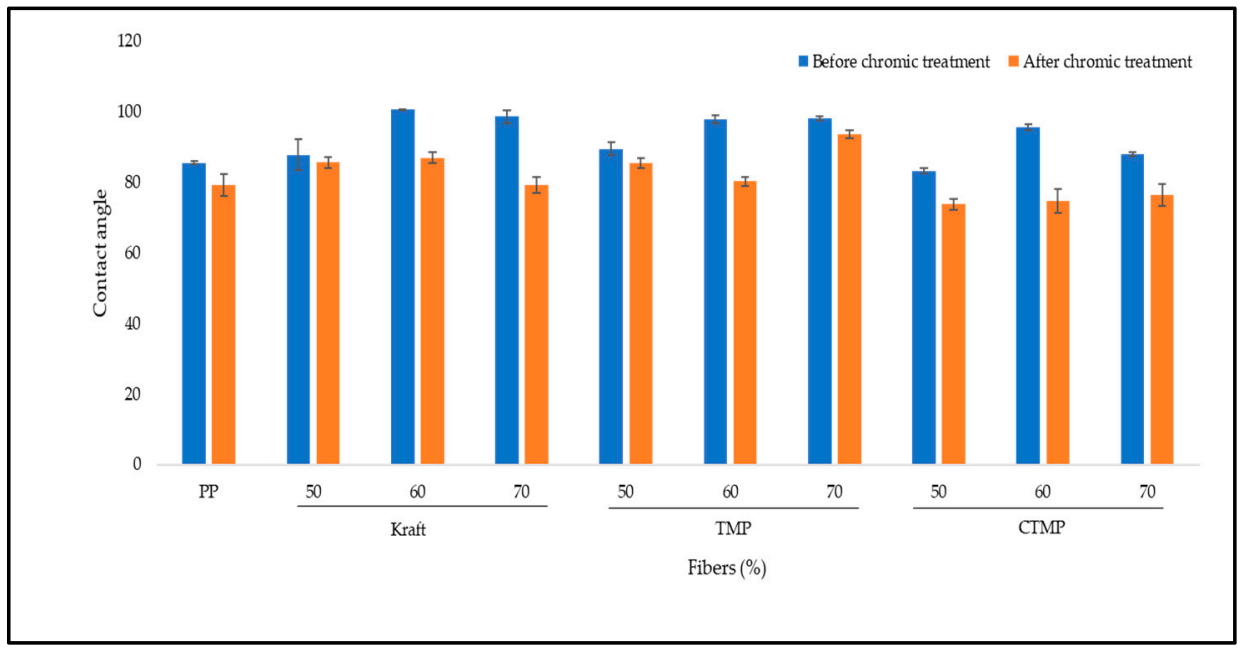

Figure 5. Contact angle evolution before and after chromic treatment.

\section{Conclusions}

The chromic treatment allowed for a more pronounced oxidation of the surfaces and a higher polarity. This treatment limited most of the wood components and exposed the PP to the surface. As a result, this treatment significantly altered the chemical composition of the surface. Improved oxidation took place due to the creation of new carbon-oxygen polar groups and increasing carbonyl and hydroxyl indices. The surface roughness of WPCs increased considerably with the chromic acid treatment. Chromic treatment probably caused cracks, pores, and surface pitting on the surface of the WPCs. This surface roughness resulted in a higher interfacial zone for bonding with the coating. In addition to this, after chromic treatment, the composites showed lower contact angles, indicating that the surface became more wettable, which would promote adhesion between the coatings and the composites.

Author Contributions: Conceptualization, A.K. and M.R.; methodology, M.R.; formal analysis, M.R., F.E. and B.B.; investigation, M.R.; resources, A.K.; data curation, M.R., F.E., B.B. and A.K.; writing—original draft preparation, M.R. and F.E.; writing—review and editing, A.K., F.G. and M.K.; supervision, A.K., F.G., M.K. and H.M.; project administration, A.K.; funding acquisition, A.K., S.M. and F.G. All authors have read and agreed to the published version of the manuscript.

Funding: This research was funded by the Canada Research Chairs Program: Grant No. 557752, Natural Sciences and Engineering Research Council of Canada, Grant No. 567663, CRIBIQ: Grant No. 2015-29-C18, and MITACS, Grant No. IT08227.

Institutional Review Board Statement: Not applicable.

Informed Consent Statement: Not applicable.

Data Availability Statement: Not applicable.

Acknowledgments: The authors would like to thank Williams Belhadef and Gilles Villeneuve for technical assistance, the CTRI for assisting in contact angle measurements.

Conflicts of Interest: The authors declare no conflict of interest.

\section{References}

1. Migneault, S.; Koubaa, A.; Perré, P.; Riedl, B. Effects of wood fiber surface chemistry on strength of wood-plastic composites. Appl. Surf. Sci. 2015, 343, 11-18. [CrossRef]

2. Gupta, B.S.; Laborie, M.-P. Surface activation and adhesion properties of wood-fiber reinforced thermoplastic composites. J. Adhes. 2007, 83, 939-955. [CrossRef]

3. Mahlberg, R.; Niemi, H.E.-M.; Denes, F.; Rowell, R.M. Effect of oxygen and hexamethyldisiloxane plasma on morphology, wettability and adhesion properties of polypropylene and lignocellulosics. Int. J. Adhes. Adhes. 1998, 18, 283-297. [CrossRef] 
4. Wolkenhauer, A.; Avramidis, G.; Hauswald, E.; Militz, H.; Viol, W. Sanding vs. plasma treatment of aged wood: A comparison with respect to surface energy. Int. J. Adhes. Adhes. 2009, 29, 18-22. [CrossRef]

5. Wang, H.; Chen, S.J.; Zhang, J. Surface treatment of LLDPE and LDPE blends by nitric acid, sulfuric acid, and chromic acid etching. Colloid Polym. Sci. 2009, 287, 541-548. [CrossRef]

6. Brewis, D.M.; Mathieson, I. Adhesion and Bonding to Polyolefins; Smithers Rapra Publishing: Shrewsbury, UK, 2001.

7. Akhtarkhavari, A.; Kortschot, M.T.; Spelt, J.K. Adhesion and durability of latex paint on wood fiber reinforced polyethylene. Prog. Org. Coat. 2004, 49, 33-41. [CrossRef]

8. Oporto, G.S.; Gardner, D.J.; Bernhardt, G.; Neivandt, D.J. Characterizing the mechanism of improved adhesion of modified wood plastic composite (WPC) surfaces. J. Adhes. Sci. Technol. 2007, 21, 1097-1116. [CrossRef]

9. Gramlich, W.; Garner, D.J.; Neivandt, D.J. Surface treatments of wood-plastic composites (WPCs) to improve adhesion. J. Adhes. Sci. Technol. 2006, 20, 1873-1887. [CrossRef]

10. Yáñez-Pacios, A.J.; Martin-Martinez, J.M. Surface modification and adhesion of wood-plastic composite (WPC) treated with UV/ozone. Compos. Interfaces 2018, 25, 127-149. [CrossRef]

11. Mirabedini, S.M.; Rahimi, H.; Hamedifar, S.; Mohseni, M. Microwave irradiation of polypropylene surface: A study on wettability and adhesion. Int. J. Adhes. Adhes. 2004, 24, 163-170. [CrossRef]

12. ASTM D2093-03(2017). Standard Practice for Preparation of Surfaces of Plastics Prior to Adhesive Bonding; ASTM International: West Conshohocken, PA, USA, 2017; Available online: https:/ / www.astm.org/Standards/D2093.htm (accessed on 20 November 2020).

13. Blais, N.C.; Truhlar, D.G. Monte Carlo trajectories: Dynamics of the reaction $\mathrm{F}+\mathrm{D}_{2}$ on a semiempirical valence-bond potential energy surface. J. Chem. Phys. 1973, 58, 1090-1108. [CrossRef]

14. Teng, X.L.; Di, M.W. Effect of liquid oxidation surface treatment on bonding properties of wood/polyethylene composites. In Applied Mechanics and Materials; Trans Tech Publications Ltd.: Freienbach, Switzerland, 2011; Volume 66-68, pp. 907-910. [CrossRef]

15. Moghadamzadeh, H.; Rahimi, H.; Asadollahzadeh, M.; Hemmati, A.R. Surface treatment of wood polymer composites for adhesive bonding. Int. J. Adhes. Adhes. 2011, 31, 816-821. [CrossRef]

16. Hou, Y.; Yan, S.; Guo, X.; Di, M. Combined surface treatment of polyethylene wood-plastic composites to achieve rapid bonding with desired adhesion properties. Bioresources 2017, 12, 6434-6445. [CrossRef]

17. Ryntz, R.A. Adhesion to Plastics Molding and Paintability; Polymer Surfaces and Interfaces Series; Globe Press: Weizback, Denmark, 1998.

18. Drnovska, H.; Lapcik, L.; Bursikova, V.; Zemek, J.; Barros-Timmons, A.M. Surface Properties of Polyethylene after LowTemperature Plasma Treatment. Colloid Polym. Sci. 2003, 281, 1025-1033. [CrossRef]

19. Bhat, N.V.; Upadhyay, D.J. Plasma-induced Surface Modification and Adhesion Enhancement of Polypropylene Surface. J. Appl. Polym. Sci. 2002, 86, 925-936. [CrossRef]

20. Strobel, M.; Sullivan, N.; Branch, M.C.; Jones, V.; Park, J.; Ulsh, M.; Strobel, J.M.; Lyons, C.S. Gas-phase Modeling of Impinging Flames used for the Flame Surface Modification of Polypropylene Film. J. Adhes. Sci. Technol. 2001, 15, 1-21. [CrossRef]

21. Gardner, D.J.; O’Neill, S.; Peterson, M.; Robinson, J. The Application of Flame Treatment to Promote Structural Adhesive Bonds in Wood Plastic Composite Laminates. In Proceedings of the 8th International Conference on Wood Fiber Plastic Composites, Madison, WI, USA, 23-25 May 2005.

22. Ranby, B.; Yang, W.T.; Tretinnikov, O. Surface Photo-grafting of Polymer Fibers, Films and Sheets. Nucl. Instrum. Methods Phys. Res. 1999, 151, 301-305. [CrossRef]

23. Blais, P.; Carlsson, D.J.; Csullog, G.W.; Wiles, D.M. The Chromic Acid Etching of Polyolefin Surfaces and Adhesive Bonding. J. Colloid Interface Sci. 1974, 47, 636-649. [CrossRef]

24. Mohamed, M.R.; Naguib, H.M.; El-Ghazawy, R.A.; Shaker, N.O.; Amer, A.A.; Soliman, A.M.; Kandil, U.F. Surface Activation of Wood Plastic Composites (WPC) for enhanced Adhesion with Epoxy Coating. Materials performance and characterization. ASTM 2019, 8, 22-40.

25. Stark, N.M.; Matuana, L.M.; Clemons, C.M. Effect of processing method on surface and weathering characteristics of woodflour/HDPE composites. J. Appl. Polym. Sci. 2004, 93, 1021-1030. [CrossRef]

26. Rudawska, A. Surface Treatment in Bonding Technology; Academic Press: London, UK, 2019; pp. 87-128. ISBN 9780128170106. Available online: https:/ /www.sciencedirect.com/science/article/pii/B9780128170106000059 (accessed on 23 November 2020).

27. Kenyence. Instrument de Mesure de Rugosité de Surface. 2020. Available online: https://www.keyence.eu/frfr/ss/products/ microscope/rouglmess/eguipment/line02.jsp (accessed on 12 February 2021).

28. Briggs, D.; Brewis, D.M.; Konieczo, M.B. X-ray photoelectron spectroscopy studies of polymer surfaces. Part 1 Chromic acid etching of polyolefins. J. Mater. Sci. 1976, 11, 1270-1277. [CrossRef]

29. Yáñez-Pacios, A.J.; Martin-Martinez, J.M. Surface modification and improved adhesion of wood-plastic composites (WPCs) made with different polymers by treatment with atmospheric pressure rotating plasma jet. Int. J. Adhes. Adhes. 2017, 77, 204-213. [CrossRef]

30. Ayrilmis, N.; Benthien, J.T.; Thoemen, H. Effects of formulation variables on surface properties of wood-plastic composites. Compos. Part B 2012, 43, 325-331. [CrossRef]

31. Sieminsky, R.; Skarzynska, A. Surface roughness of different species of wood after sanding. Przem. Drzewny 1987, 38, 23-25. 